\title{
Downregulation of midkine induces cisplatin resistance in human oral squamous cell carcinoma
}

\author{
TOMOKO OTA $^{1,2}$, HIROFUMI JONO ${ }^{2}$, KAZUTOSHI OTA ${ }^{1}$, SATORU SHINRIKI ${ }^{2}$, \\ MITSUHARU UEDA ${ }^{2}$, TAKANAO SUEYOSHI ${ }^{2,3}$, KEN NAKATANI ${ }^{4}$, YUKIHIRO HIRAISHI ${ }^{4}$, \\ TAKESHI WADA ${ }^{4}$, SHIGEYUKI FUJITA ${ }^{4}$, KONEN OBAYASHI ${ }^{2}$, MASANORI SHINOHARA $^{1}$ and YUKIO ANDO ${ }^{2}$ \\ Departments of ${ }^{1}$ Oral and Maxillofacial Surgery, ${ }^{2}$ Diagnostic Medicine and ${ }^{3}$ Orthopaedic and Neuro-Musculoskeletal \\ Surgery, Graduate School of Medical Sciences, Kumamoto University, Kumamoto 860-8556; ${ }^{4}$ Department \\ of Oral and Maxillofacial Surgery, Wakayama Medical University, Wakayama 641-8509, Japan
}

Received November 18, 2011; Accepted January 19, 2012

DOI: 10.3892/or.2012.1684

\begin{abstract}
The presence of drug-resistant cancer cells has been associated with poor clinical outcomes. Cisplatin is one of the most effective chemotherapeutic agents commonly used for several malignancies including oral squamous cell carcinoma (OSCC). Although cisplatin resistance is a major obstacle in cancer treatment, mechanisms by which it develops are not well understood. Midkine (MK), a heparin-binding growth factor, has various cancer-related functions. In this study, we investigated whether MK is involved in cisplatin resistance in OSCC. We demonstrated that the Sa-3R cell line, which is OSCC cisplatin-resistant, exhibited lower MK expression with slow growth compared with its parent, Sa-3 cells. In Sa-3 cells, downregulation of MK expression significantly reduced cisplatin sensitivity, cell growth, and the expression of cyclin D1 and cyclin E1. MK knockdown suppressed cellular cisplatin accumulation via induction of ATP-binding cassette efflux transporters. These data suggest that MK may play important roles in cisplatin resistance in OSCC by modulating both cell growth and intracellular cisplatin accumulation.
\end{abstract}

\section{Introduction}

Oral cancer is a common type of human cancer $(1,2)$. More than $90 \%$ of oral malignancies are histologically oral squamous cell carcinoma (OSCC). About 275,000 people worldwide are annually diagnosed with $\operatorname{OSCC}(1,3)$. Despite advances in early detection, diagnosis, and multimodal treatment, the 5-year survival rate for patients with OSCC has not

Correspondence to: Dr Yukio Ando, Department of Diagnostic Medicine, Graduate School of Medical Sciences, Kumamoto University, 1-1-1 Honjo, Kumamoto 860-8556, Japan

E-mail: andoy709@kumamoto-u.ac.jp

Key words: midkine, oral squamous cell carcinoma, drug resistance, cisplatin improved in the past few decades but has remained at 50\% $(4,5)$. Chemotherapy of OSCC benefits patients with advanced cancers, producing smaller tumors, reduced metastasis and recurrence, and improved prognosis (6).

Cisplatin (cis-diamminedichloroplatinum II: CDDP), which is an alkylating agent, is one of the most effective and commonly used chemotherapeutic agents for OSCC and many other solid tumors including testicular, ovarian, cervical and non-small-cell lung cancer (7). However, despite the efficacy of cisplatin in the treatment of these tumors, development of resistance to this drug, intrinsic or acquired, is a major obstacle to its successful clinical application in $\operatorname{OSCC}(8,9)$. Although multiple mechanisms underlying cisplatin resistance have been described for many types of cancer cells including OSCC cells (10), the molecular signature that defines the cisplatin-resistant phenotype has been thought to differ among tumor types and to be affected by environmental factors (9), and the precise molecular mechanisms of the resistance have not been fully elucidated. Better understanding of the molecular signature of cisplatin-resistant populations is therefore needed.

Midkine (MK), which is a heparin-binding growth factor, was first identified as the product of a retinoic acid-induced gene. MK has various well-known cancer-related functions, in, for example, survival, mitogenesis, transformation, angiogenesis, anti-apoptosis, and cell growth (11). Previous studies reported intense MK expression at tissue and serum levels in different human cancers including OSCC $(11,12)$, and association with poor prognosis in some cancers (12-14). Although accumulating evidence shows that MK has important roles in tumor progression as mentioned above, little is known about its involvement in drug resistance.

In the present study, we investigated the involvement of MK in cisplatin resistance in OSCC by using two OSCC cell lines, Sa-3 and its cisplatin-resistant subline Sa-3R.

\section{Materials and methods}

Cell lines and cell cultures. The human OSCC cell line Sa-3 and its cisplatin-resistant subline Sa-3R were established as previously described (15). Briefly, the Sa-3 cell line was derived from a biopsy specimen of well-differentiated upper 
gingival OSCC (15). The cisplatin-resistant subline Sa-3R was established by repeated subculturing in the presence of increasing concentrations of cisplatin from $0.1 \mu \mathrm{g} / \mathrm{ml}$ until the cells became fully resistant to cisplatin and grew exponentially in the final concentration of $0.5 \mu \mathrm{g} / \mathrm{ml}$. The Sa-3R cell line showed no loss of resistance even after 6-months of culture in a drug-free medium (15). Other human OSCC cell lines-SAS, HSC-3, Ca9-22, NA, SCC-KN, and TU-4-were kindly provided by Dr Shirasuna (Department of Oral and Maxillofacial Surgery, Graduate School of Dental Science, Kyushu University; Fukuoka, Japan). All cell lines were grown in Dulbecco's modified Eagle's medium (DMEM) (Gibco, Carlsbad, CA) with $10 \%$ heat-inactivated fetal bovine serum (Gibco), $100 \mathrm{U} / \mathrm{ml}$ penicillin, and $100 \mu \mathrm{g} / \mathrm{ml}$ streptomycin (Gibco) in $5 \% \mathrm{CO}_{2}$ at $37^{\circ} \mathrm{C}$. Cisplatin was kindly provided by Nippon Kayaku (Tokyo, Japan).

$R N A$ isolation and real-time quantitative reverse transcription-PCR $(q-P C R)$. Total RNA was isolated from cells by using the TRIzol reagent (Invitrogen, Tokyo, Japan) and was quantified with a NanoVue spectrophotometer (GE Healthcare, Tokyo, Japan). Total RNA $(0.5 \mu \mathrm{g})$ was reversetranscribed to complementary DNA (cDNA) by means of the ExScript RT reagent kit (Takara Bio Inc., Otsu, Japan) according to the manufacturer's instructions. Each PCR cycle was performed with $2 \mu \mathrm{l}$ of cDNA and each primer at $0.2 \mu \mathrm{M}$ in a LightCycler System with SYBR Premix Ex Taq (Takara Bio Inc.). The following primers were used: MK forward: 5'-AGATGCAGCACCGAGGCT-3', MK reverse: 5'-CTT T CTTTTTGGCGACCG-3'; $\beta$-actin forward: 5'-TGGCACCC AGCACAATGAA-3', $\beta$-actin reverse: 5'-CTAAGTCATAG TCCGCCTAGAAGCA-3'; cyclin D1 forward: 5'-TATTGC GCTACCGTTGAC-3', cyclin D1 reverse: 5'-CCAATAGCA GCAAACAATGTGAAA-3'; cyclin E1 forward: 5'-GATTG GTTAATGGAGGTGTGTGAA-3', cyclin E1 reverse: 5'-CG CCATATACCGGTCAAAGAA-3'; multidrug resistance protein 1 (MDR1) forward: 5'-TTGGTGGCACATAAA CTC-3', MDR1 reverse: 5'-ATGTGGGCTGCTGATATT-3'; and multidrug resistance-associated protein (MRP1) forward: 5'-GCTGATGGAGGCTGACAA-3', MRP1 reverse: 5'-CGCGGACACATGGTTACA-3'. PCR reactions were performed by using the following conditions: initialisation for $10 \mathrm{sec}$ at $95{ }^{\circ} \mathrm{C}$ and then 45 cycles of amplification, including denaturation for $5 \mathrm{sec}$ at $95^{\circ} \mathrm{C}$ and $20 \mathrm{sec}$ at $60^{\circ} \mathrm{C}$ for annealing and elongation. After amplification, the temperature was slowly raised to higher than the melting temperature of the PCR product for measurement of fluorescence and thereby determination of the melting curve. All standards and samples were analyzed in triplicate.

Automated fluorescent-enzyme immunoassay (FEIA) for $M K$. The MK FEIA, a two-site immunoenzymometric assay requiring $50-\mu \mathrm{l}$ samples, was performed automatically with the AIA-600II immunoassay analyser (Tosoh Corp., Tokyo, Japan) as previously described (12). For samples, conditioned medium was produced by incubating Sa-3 and Sa3-R cells that grew to $80 \%$ confluence in 6 -well plates after $48 \mathrm{~h}$. MK in samples was reacted simultaneously with alkaline phosphatase-labelled mouse anti-MK monoclonal antibody (SC-4) and with mouse anti-MK monoclonal antibody (SC-2) immobilised on magnetisable beads to form a sandwich structure. The beads were washed after $10 \mathrm{~min}$ of incubation at $37^{\circ} \mathrm{C}$ to remove unbound materials. For the enzyme-substrate reaction at $37^{\circ} \mathrm{C}$ for $5 \mathrm{~min}$, the fluorogenic substrate 4-methylumbelliferyl phosphate was added. The rate of fluorescence of converted 4-methylumbelliferone was directly proportional to MK concentrations in samples.

Transfection with small interfering RNA (siRNA). Sa-3 cells were incubated in 12-well or 96-well plates for $24 \mathrm{~h}$ and were transiently transfected with $50 \mathrm{nM}$ siRNA by using Lipofectamine RNAiMAX (Invitrogen) according to the manufacturer's protocol. After transfection and incubation for 24-48 h, experiments were performed. Silencer Negative Control no. 1 siRNA (Ambion/Applied Biosystems, Foster City, CA) was used as the control. The MK siRNA sequences were sense: 5'-GGGAUUCUGGGAAGCUUGAtt-3' and antisense: 5'-UCAAGCUUCCCAGAAUCCCtt-3' (Ambion, Applied Biosystems).

Analysis of cell survival rate. Cisplatin sensitivity was measured by using the MTS assay to evaluate inhibition of cell growth with the CellTiter 96 AQueous One Solution reagent (Promega, Madison, WI) as previously described (16). Cells were incubated, in triplicate, in 96-well plates and were treated with different cisplatin concentrations $(0-20 \mu \mathrm{g} / \mathrm{ml})$. After $24 \mathrm{~h}$ of cisplatin treatment, the medium was changed to drug-free DMEM and incubation continued for an additional $72 \mathrm{~h}$ with a final volume of $100 \mu \mathrm{l}$. Then, $20 \mu \mathrm{l}$ of CellTiter 96 Aqueous One Solution reagent was added to each well. After a 4-h incubation, absorbance was measured at $490 \mathrm{~nm}$ by using the EMax Precision Microplate Reader (Molecular Devices, Osaka, Japan). The $50 \%$ inhibitory concentration $\left(\mathrm{IC}_{50}\right)$ was calculated from survival curves.

Cell cycle analysis. Flow cytometry after staining with propidium iodide (PI) (Calbiochem, San Diego, CA) was utilized for cell cycle analysis. Cells were incubated in 12-well plates and then harvested. Cells were washed in PBS at $4^{\circ} \mathrm{C}$, fixed in cold ethanol $(70 \%)$ at $4^{\circ} \mathrm{C}$ overnight, digested with RNase A $(0.1 \mu \mathrm{g} / \mathrm{ml})$, stained with PI $(25 \mu \mathrm{g} / \mathrm{ml})$, and analysed with an FACSCalibur Flow Cytometer (BD Biosciences, Franklin Lakes, NJ). Histograms were analysed by using ModFit software (Verity Software House, Topsham, ME).

Inductively coupled plasma mass spectrometry (ICP-MS). Cells were incubated in 12-well plates and treated with cisplatin (1-20 $\mu \mathrm{g} / \mathrm{ml})$ in serum-free medium. After $0.5-3 \mathrm{~h}$ of incubation, samples were harvested and ICP-MS (Finnigan MAT Element; ThermoQuest, Bremen, Germany) was performed. After incubation for different time periods, cells were washed four times with ice-cold PBS and solubilised by direct addition of $1 \mathrm{ml}$ of $70 \%$ nitric acid. After $10 \mathrm{~min}$ of incubation at room temperature, digested samples were harvested, diluted to $5 \mathrm{ml}$ by addition of $0.5 \%$ nitric acid, and analysed via ICP-MS. All samples were quantitated by using external standard solutions made up in $0.5 \%$ nitric acid. The blank solution was $0.5 \%$ nitric acid. The protein concentration was measured by using the BCA Protein Assay Kit (Pierce, Rockford, IL) according to the manufacturer's instructions. 
A

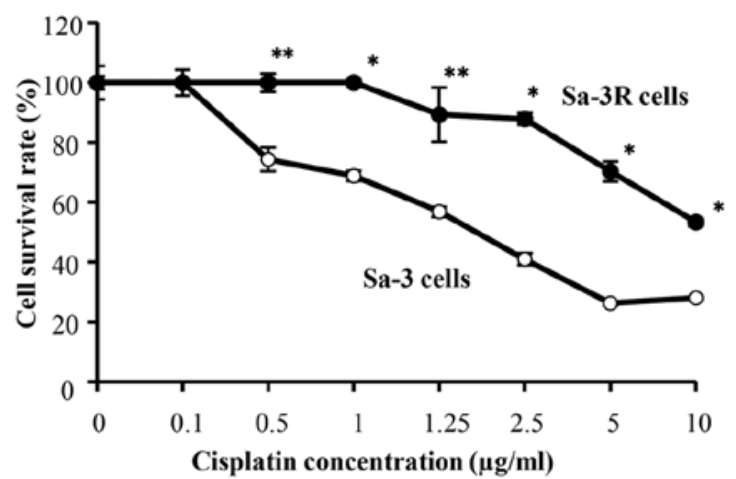

B

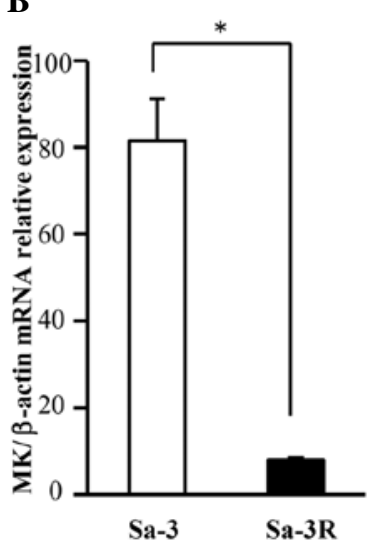

C

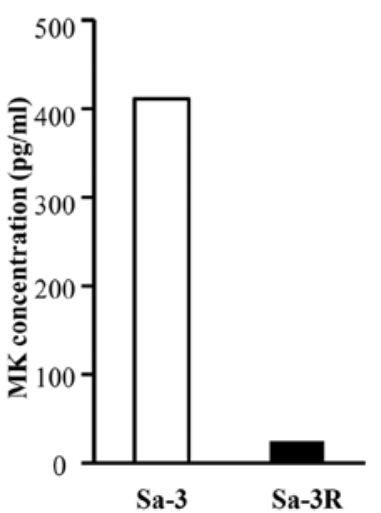

Figure 1. (A) Survival rate of $\mathrm{Sa}-3$ and $\mathrm{Sa}-3 \mathrm{R}$ cells after cisplatin treatment. Sa-3 and Sa-3R cells were treated with cisplatin at concentrations as indicated in the figure. Cell viability was measured by the MTS assay and described as a percentage relative to control cells for each cell line. ${ }^{*} \mathrm{P}<0.001 ;{ }^{* * *} \mathrm{P}<0.01$. Open and closed circles indicate Sa-3 and Sa-3R cells, respectively. (B and C) Comparison of MK expression in Sa-3 and Sa3-R cells. MK mRNA expression was measured by means of q-PCR (B), and MK protein expression in conditioned medium was measured by using FEIA (C). ${ }^{*} \mathrm{P}<0.001$.

Statistical analysis. Student's t-test and analysis of variance were used to evaluate differences between the two groups. All analyses were performed with JMP software Version 5.1 for Windows (SAS Institute Japan, Tokyo, Japan). The correlation between $\mathrm{MK}$ expression and $\mathrm{IC}_{50}$ of cisplatin was calculated by using the Pearson's product-moment correlation coefficient. $P$-values of $<0.05$ were said to be statistically significant.

\section{Results}

Cisplatin sensitivity and $M K$ expression in $\mathrm{Sa}-3$ and $\mathrm{Sa}-3 \mathrm{R}$ cells. We first confirmed the sensitivity of Sa-3 and Sa-3R cells to cisplatin by means of the MTS assay. Consistent with results in a previous study (15), the sensitivity of Sa-3R cells to cisplatin $\left(\mathrm{IC}_{50}, 10.0 \mu \mathrm{g} / \mathrm{ml}\right)$ was approximately 7 -fold less than that of Sa-3 cells ( $\left.\mathrm{IC}_{50}, 1.5 \mu \mathrm{g} / \mathrm{ml}\right)$ (Fig. 1A). We then analysed the MK expression in Sa-3 and Sa-3R cells at both the mRNA and protein levels by means of q-PCR and FEIA, respectively. Fig. 1B shows significantly lower MK expression in Sa-3R cells than in Sa-3 cells at the mRNA level $(\mathrm{P}<0.001)$. Sa-3R cells also evidenced lower MK protein expression than did Sa-3 cells (Fig. 1C).

A

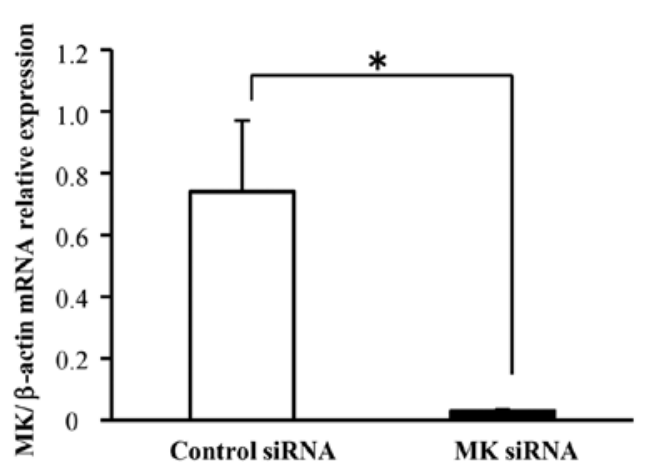

B

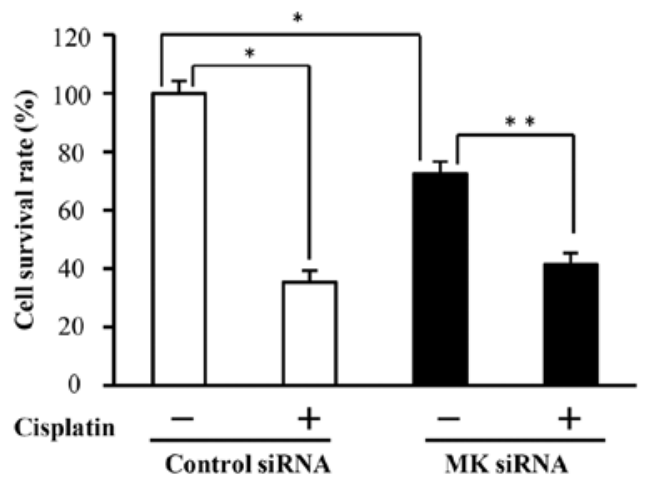

C

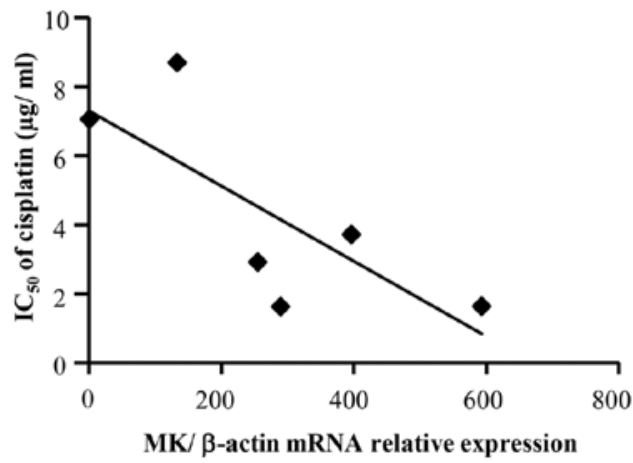

Figure 2. (A) Efficacy of MK-specific siRNA in Sa-3 cells. Cells were transfected with $50 \mathrm{nM}$ siRNA, and the level of MK mRNA expression was measured by means of q-PCR. ${ }^{*} \mathrm{P}<0.001$. (B) Survival rate of Sa-3 cells transfected with MK siRNA or control siRNA after cisplatin treatment. Cells transfected with $50 \mathrm{nM}$ siRNA were treated with cisplatin $(1 \mu \mathrm{g} / \mathrm{ml})$, and cell viability was evaluated using the MTS assay. ${ }^{*} \mathrm{P}<0.001 ;{ }^{* * *} \mathrm{P}<0.05$. (C) Correlation between $\mathrm{MK}$ expression and $\mathrm{IC}_{50}$ of cisplatin in different human OSCC cell lines: SAS, HSC-3, Ca9-22, NA, SCC-KN, and TU-4. Cell lines were treated with various concentrations of cisplatin $(0-20 \mu \mathrm{g} / \mathrm{ml})$, and $\mathrm{IC}_{50}$ values were determined via the MTS assay. MK mRNA expression was measured by means of q-PCR. $(r=-0.70, y=-0.0109 x+7.3089)$.

Downregulation of MK expression resulted in decreased cisplatin sensitivity. To determine whether MK is involved in cisplatin resistance in OSCC, we next evaluated the effect of MK knockdown by siRNA on cisplatin sensitivity of Sa-3 cells. MK-specific siRNA efficiently reduced endogenous mRNA expression of MK approximately $80 \%$ compared with control siRNA $(\mathrm{P}<0.001)$ (Fig. 2A). Fig. 2B shows that Sa-3 cells transfected with MK siRNA exhibited higher cell viability after cisplatin treatment (43.0\% inhibition) than did cells transfected with control siRNA (64.6\% inhibition), which suggests that Sa-3 cells showed reduced sensitivity 
A

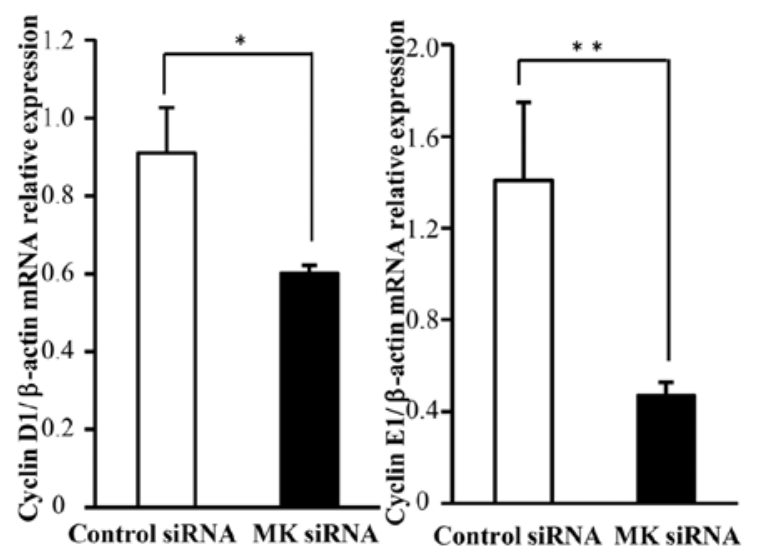

B

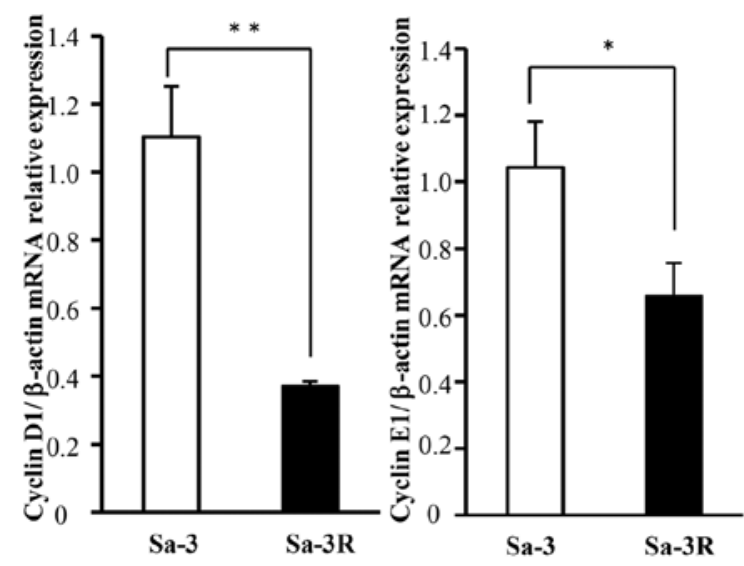

Figure 3. Comparison of the expression of cell cycle regulatory genes. Expression levels of cyclin D1 and cyclin E1 were measured by means of q-PCR. (A) Effect of MK knockdown on expression of cyclin D1 mRNA (left panel) and cyclin E1 mRNA (right panel) in Sa-3 cells. (B) Expression of cyclin D1 mRNA (left panel) and cyclin E1 mRNA (right panel) in Sa-3 and Sa-3R cells. ${ }^{*} \mathrm{P}<0.05 ;{ }^{* *} \mathrm{P}<0.01$.

to cisplatin by downregulating MK expression. In addition, to determine whether cisplatin sensitivity in OSCC is associated with MK expression, we analysed the correlation between $\mathrm{MK}$ expression and $\mathrm{IC}_{50}$ value of cisplatin in different human OSCC cell lines. $\mathrm{IC}_{50}$ values for SAS, HSC-3, Ca9-22, NA, SCC-KN, and TU-4 were 1.64, 1.63, 3.72, 2.92, 7.06 , and $8.70 \mu \mathrm{g} / \mathrm{ml}$, respectively. The $\mathrm{IC}_{50}$ values tended to be higher in cell lines with low MK expression $(r=-0.70$, $y=-0.0109 x+7.3089)$ (Fig. 2C).

Downregulation of MK expression inhibited cell growth. The fact that inhibition of cell growth causes resistance to anticancer chemotherapeutic agents (17) and that MK positively regulates tumour cell growth are well documented $(17,18)$. Because we found that $\mathrm{Sa}-3$ cell viability was reduced by downregulation of MK in the absence of cisplatin (Fig. 2B), we first focused on MK-induced promotion of cell growth to investigate the mechanism underlying MK-mediated cisplatin resistance. To evaluate the effect of MK knockdown on the growth of Sa-3 cells, we performed cell cycle analysis with flow cytometry. The percentage of Sa-3 cells in $G_{0} / G_{1}$ phase
Table I. Effect of MK knockdown on the growth of Sa-3 cells and comparison of growth rates of Sa-3 and Sa-3R cells in serum-free medium.

\begin{tabular}{lccc}
\hline & \multicolumn{3}{c}{ Cells in cell cycle phases $(\%)$} \\
\cline { 2 - 4 } Cell lines and conditions & $\mathrm{G}_{0} / \mathrm{G}_{1}$ & $\mathrm{~S}$ & $\mathrm{G}_{2} / \mathrm{M}$ \\
\hline MK knockdown & & & \\
Control siRNA (Sa-3) & $64.97 \pm 1.32$ & $28.77 \pm 2.04$ & $6.27 \pm 2.12$ \\
MK siRNA (Sa-3) & $72.04 \pm 0.61^{\mathrm{a}}$ & $20.33 \pm 0.55^{\mathrm{a}}$ & $7.63 \pm 0.64$ \\
Comparison of cell lines & & & \\
Sa-3 & $64.62 \pm 0.94$ & $28.21 \pm 2.21$ & $7.15 \pm 1.46$ \\
Sa-3R & $82.54 \pm 0.92^{\mathrm{b}}$ & $12.22 \pm 0.82^{\mathrm{b}}$ & $5.24 \pm 0.13$ \\
\hline
\end{tabular}

${ }^{\mathrm{a}} \mathrm{P}<0.01,{ }^{\mathrm{b}} \mathrm{P}<0.001$.

was significantly higher but that in the S-phase was significantly lower in cells transfected with MK siRNA compared with those transfected with control siRNA (Table I), which indicates that $\mathrm{MK}$ knockdown led to $\mathrm{G}_{1}$ arrest. To determine how downregulation of MK led to growth inhibition, we next evaluated expression levels of cell cycle regulatory genes by means of q-PCR. Consistent with results from cell cycle analysis, expression levels of cyclin D1 and cyclin E1, both of which participate in progression of the cell cycle during $\mathrm{G}_{1}-\mathrm{S}$ phases, were significantly reduced by MK knockdown in Sa-3 cells (Fig. 3A). These results indicated that MK downregulation suppressed growth of Sa-3 cells by controlling expression of cell cycle regulator genes. In agreement with these results, Sa-3R cells, which exhibited lower MK expression as well as cisplatin resistance, had a significantly higher percentage of the cell population in the $G_{1}$ phase and a significantly lower percentage in the $\mathrm{S}$ phase, compared with Sa-3 cells (Table I). In addition, expression levels of cyclin D1 and cyclin E1 were significantly lower in Sa-3R cells than in Sa-3 cells (Fig. 3B).

Downregulation of $M K$ reduced cellular accumulation of cisplatin. One of the main reasons for cisplatin resistance has been reduced drug accumulation $(19,20)$. A previous study reported that overexpression of MDR1, MRP1, and MRP2, which are drug efflux transporters that belong to the ATP-binding cassette (ABC) family, was associated with the mechanism of acquired cisplatin resistance in Sa-3R cells (15). We thus sought to determine, by using ICP-MS, the level of cisplatin accumulation in both Sa-3 cells and Sa-3R cells. As indicated in Fig. 4A, Sa-3R cells, which had lower MK expression, accumulated less cisplatin than did Sa-3 cells in a dose- and time-dependent manner. Expression levels of MDR1 and MRP1 in Sa-3R cells were significantly higher than those in Sa-3 cells (Fig. 4B). Therefore, we investigated whether MK expression was correlated with cellular accumulation of cisplatin. As presented in Fig. 5A, we found that MK knockdown by siRNA reduced cisplatin accumulation in Sa-3 cells compared with control siRNA. We also found that MK knockdown increased the expression levels of MDR1 and MRP1 mRNA in Sa-3 cells (Fig. 5B). 
A
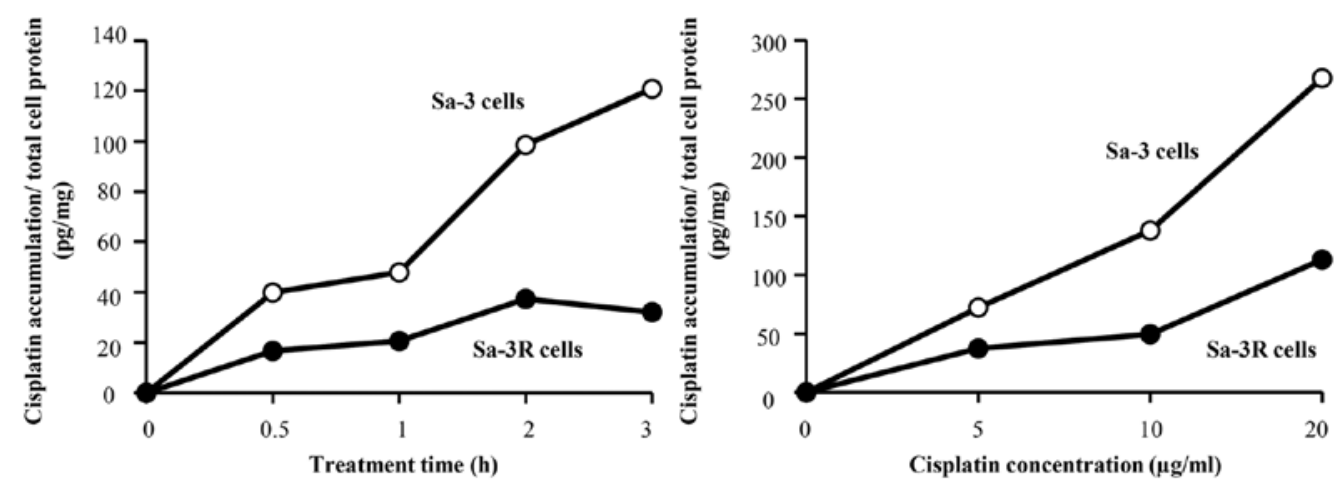

B
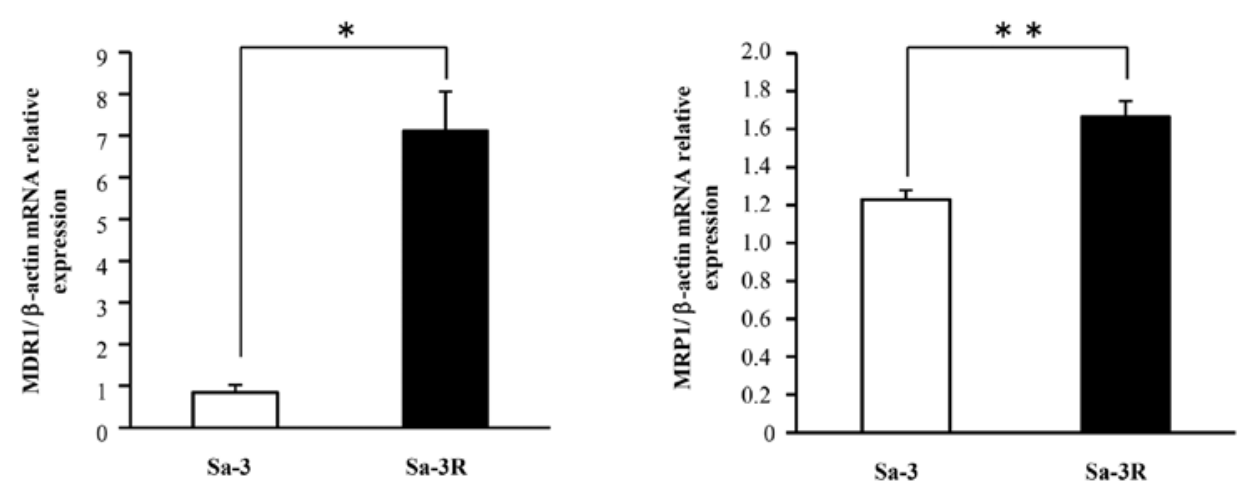

Figure 4. (A) Cisplatin accumulation in Sa-3 and Sa-3R cells. Cells were treated with $10 \mu \mathrm{g} / \mathrm{ml}$ cisplatin for the indicated time periods (left panel) or at the indicated cisplatin doses for $2 \mathrm{~h}$ (right panel), and cisplatin accumulation was measured by using ICP-MS. Open and closed circles indicate Sa-3 and Sa-3R cells, respectively. (B) Comparison of the expression levels of MDR1 mRNA and MRP1 mRNA in Sa-3 cells and Sa-3R cells. MDR1 (left panel) and MRP1 (right panel) mRNA expression levels were measured by means of q-PCR. ${ }^{*} \mathrm{P}<0.001 ;{ }^{* *} \mathrm{P}<0.01$.

A
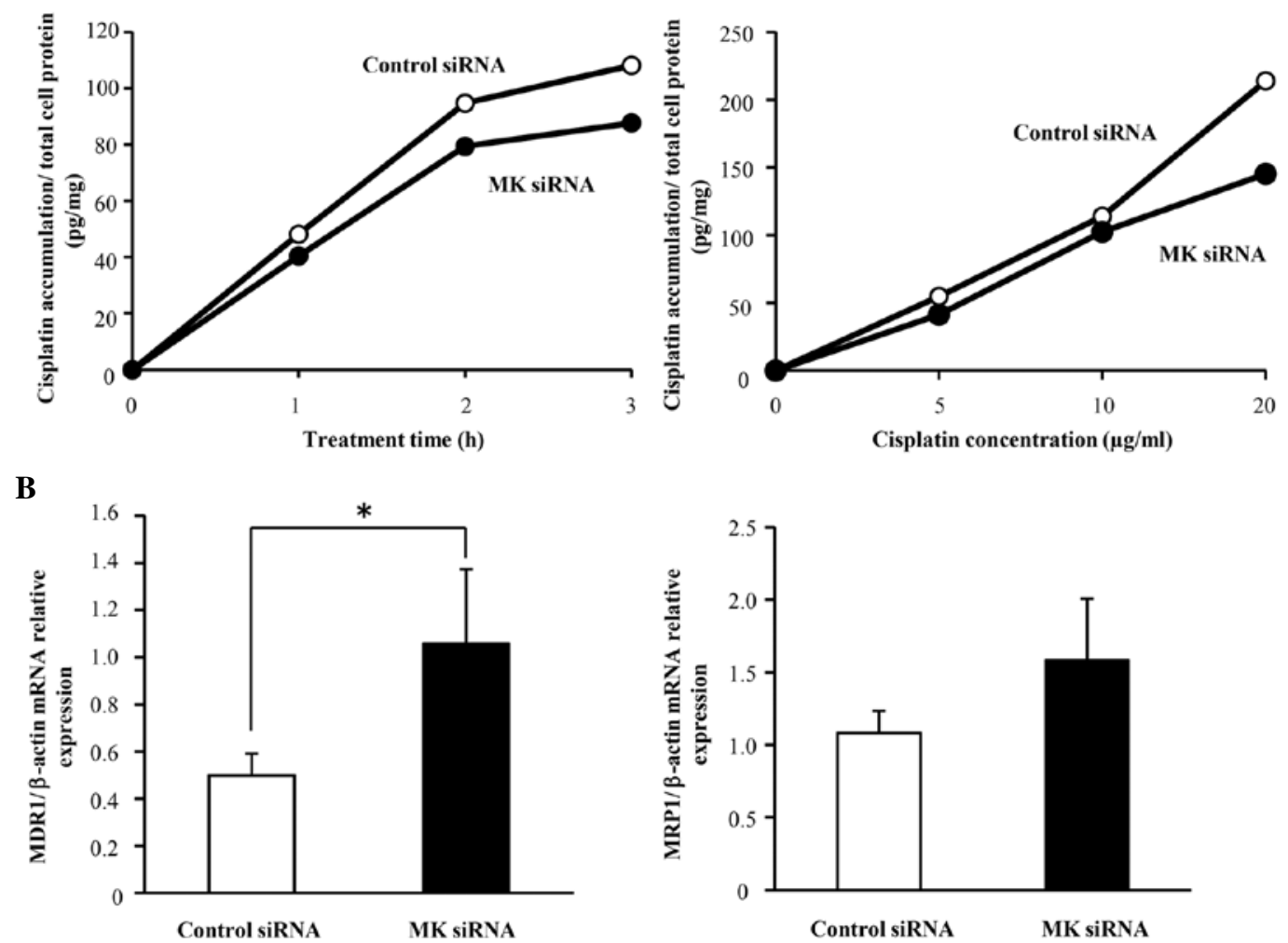

Figure 5. (A) Accumulation of cisplatin in Sa-3 cells transfected with MK siRNA. Cells were treated with $10 \mu \mathrm{g} / \mathrm{ml}$ cisplatin for the indicated time periods (left panel) or at the indicated cisplatin doses for $2 \mathrm{~h}$ (right panel), and cisplatin accumulation was measured by using ICP-MS. Open and closed circles indicate Sa-3 cells transfected with control siRNA and MK siRNA, respectively. (B) Effect of MK knockdown on expression of MDR1 mRNA and MRP1 mRNA in Sa-3 cells. MDR1 (left panel) and MRP1 (right panel) mRNA expression levels were measured by means of q-PCR. " $\mathrm{P}<0.05$. 


\section{Discussion}

The development of tumor drug resistance is responsible for poor overall survival of patients with most types of cancer (21). Our present study revealed the association of low expression of MK with cisplatin resistance. MK is a well-known growth factor and positively regulates cell proliferation via the $\mathrm{Src} /$ extracellular signal-regulated kinase/mitogen-activated protein kinase pathway and phosphoinositide 3-kinase/Akt pathway $(17,18)$. In the present study, we evaluated the effect of MK knockdown on cisplatin sensitivity, with a focus on cell proliferation. As expected, downregulation of MK expression in cisplatin-sensitive Sa-3 cells led to decreased cell growth, cell cycle arrest, and reduced expression of cyclin D1, consistent with a previous report (22), as well as reduced expression of cyclin E1. A more notable finding, however, was the significantly decreased cisplatin sensitivity caused by MK knockdown. In cisplatin-resistant Sa-3R cells, we found that not only MK expression was significantly lower but also cell cycle progression was suppressed compared with Sa-3 cells. These results suggest that the reduced cell growth mediated by MK knockdown is involved in acquisition of cisplatin resistance. Despite the importance of reduced cell growth in drug resistance, the precise molecular mechanisms linking these phenotypic signatures are not well understood. Possible explanations include the findings that inhibition of cell growth benefits DNA repair activity (23) and that cells undergoing growth arrest are protected from apoptosis and exhibit resistance to chemotherapeutic agents (24). Further investigation is needed to clarify whether reduced cell proliferation mediated by MK knockdown can contribute to cisplatin resistance via these or other mechanisms.

One main reason for cisplatin resistance is reduced drug accumulation (20). Decreased cellular accumulation of cisplatin has often been accompanied by a change in cellular uptake and efflux of cisplatin. Cellular uptake and efflux of cisplatin are mediated by transporters and carriers such as P-glycoprotein, MRP family members, and copper transporters $(10,25)$. We confirmed that Sa-3R cells, compared with Sa-3 cells, expressed higher levels of MDR1 and MRP1, which are $\mathrm{ABC}$ efflux transporters, as previously reported (15). We also demonstrated that cellular cisplatin accumulation decreased in Sa-3R cells compared with Sa-3 cells, which indicates that drug efflux systems contributed to acquisition of cisplatin resistance in Sa-3R cells. Those transporters have been documented as largely responsible for drug efflux and have been associated with drug resistance in various types of malignancies (19). In this study, we first demonstrated that downregulation of MK expression caused reduced cellular cisplatin accumulation through upregulation of MDR1 and MRP1 expression in Sa-3 cells. These data suggest that this decreased cellular cisplatin accumulation mediated by MK knockdown is attributable to increased expression of the drug efflux transporters. However, additional studies are required to elucidate the mechanism by which MK knockdown contributes to induction of MDR1 and MRP1.

Certain previous studies reported that MK rescued Wilms' tumor cells from cisplatin-induced apoptosis via upregulation of Bcl-2 (26) and that increased MK expression exerted a cytoprotective effect against doxorubicin in drug-sensitive cells, (27) which suggest that MK induces cancer cell to resist chemotherapeutic agents. In contrast to those findings, our data clearly indicated that low MK expression contributed to cisplatin resistance. In our study, although MK downregulation indeed induced considerable apoptosis after cell cycle arrest in Sa-3 cells, MK repression clearly decreased the growthinhibitory effect of cisplatin and cisplatin-induced apoptosis (data not shown).

Because our results may have derived from cell linespecific phenomena, we attempted to confirm our findings by using different human OSCC cell lines. Our results showed that cisplatin sensitivity tended to be lower in cell lines with low expression of MK. This finding suggests that downregulation of MK expression generally led to reduced cisplatin sensitivity of OSCC cells. The existence of a cisplatin-resistant cell population that does not express detectable levels of MK even in tumors that highly express $\mathrm{MK}$ at the whole tissue level may be possible. Additional studies are needed to address the functional diversity of MK, including whether such functions depend on secreted MK during the acquisition of cisplatin resistance by different types of tumors.

In conclusion, we here provided the first evidence that low expression of MK was associated with cisplatin resistance in OSCC cells through inhibiting cell growth and decreasing cellular accumulation of cisplatin. Understanding the precise molecular mechanisms and clinical significance of our findings in OSCC and other malignancies will require additional investigations.

\section{Acknowledgements}

The authors' study was supported by Grants-in-Aid for scientific research (B) 21253742 (Y.A.), (B) 21390541 (M.S.), and (C) 22592240 (K.O.) from the Ministry of Education, Science, Sports and Culture of Japan.

\section{References}

1. Jemal A, Siegel R, Ward E, et al: Cancer statistics, 2006. CA Cancer J Clin 56: 106-130, 2006.

2. Petersen PE: The World Oral Health Report 2003: continuous improvement of oral health in the 21 st century - the approach of the WHO Global Oral Health Programme. Community Dent Oral Epidemiol 31 (Suppl 1): 3-23, 2003.

3. Parkin DM, Bray F, Ferlay J and Pisani P: Global cancer statistics, 2002. CA Cancer J Clin 55: 74-108, 2005.

4. Forastiere AA, Goepfert H, Maor M, et al: Concurrent chemotherapy and radiotherapy for organ preservation in advanced laryngeal cancer. N Engl J Med 349: 2091-2098, 2003.

5. Jemal A, Siegel R, Ward E, Murray T, Xu J and Thun MJ: Cancer statistics, 2007. CA Cancer J Clin 57: 43-66, 2007.

6. Pignon JP, Bourhis J, Domenge C and Designe L: Chemotherapy added to locoregional treatment for head and neck squamouscell carcinoma: three meta-analyses of updated individual data. MACH-NC Collaborative Group. Meta-Analysis of Chemotherapy on Head and Neck Cancer. Lancet 355: 949-955, 2000.

7. Jamieson ER and Lippard SJ: Structure, recognition, and processing of cisplatin-DNA adducts. Chem Rev 99: 2467-2498, 1999.

8. Brozovic A and Osmak M: Activation of mitogen-activated protein kinases by cisplatin and their role in cisplatin-resistance. Cancer Lett 251: 1-16, 2007.

9. Zhang P, Zhang Z, Zhou X, Qiu W, Chen F and Chen W: Identification of genes associated with cisplatin resistance in human oral squamous cell carcinoma cell line. BMC Cancer 6: 224, 2006. 
10. Wang D and Lippard SJ: Cellular processing of platinum anticancer drugs. Nat Rev Drug Discov 4: 307-320, 2005.

11. Kadomatsu K and Muramatsu T: Midkine and pleiotrophin in neural development and cancer. Cancer Lett 204: 127-143, 2004.

12. Ota $\mathrm{K}$, Fujimori $\mathrm{H}$, Ueda $\mathrm{M}$, et al: Midkine as a prognostic biomarker in oral squamous cell carcinoma. Br J Cancer 99: $655-662,2008$

13. Nakagawara A, Milbrandt J, Muramatsu T, et al: Differential expression of pleiotrophin and midkine in advanced neuroblastomas. Cancer Res 55: 1792-1797, 1995.

14. Mishima K, Asai A, Kadomatsu K, et al: Increased expression of midkine during the progression of human astrocytomas. Neurosci Lett 233: 29-32, 1997.

15. Nakatani K, Nakamura M, Uzawa K, et al: Establishment and gene analysis of a cisplatin-resistant cell line, Sa-3R, derived from oral squamous cell carcinoma. Oncol Rep 13: 709-714, 2005.

16. O'Toole SA, Sheppard BL, McGuinness EP, Gleeson NC, Yoneda $\mathrm{M}$ and Bonnar J: The MTS assay as an indicator of chemosensitivity/resistance in malignant gynaecological tumours. Cancer Detect Prev 27: 47-54, 2003.

17. Sandra F, Harada H, Nakamura $\mathrm{N}$ and Ohishi M: Midkine induced growth of ameloblastoma through MAPK and Akt pathways. Oral Oncol 40: 274-280, 2004.

18. Jin Z, Lahat G, Korchin B, et al: Midkine enhances soft-tissue sarcoma growth: a possible novel therapeutic target. Clin Cancer Res 14: 5033-5042, 2008
19. Ahmed Z, Deyama Y, Yoshimura Y and Suzuki K: Cisplatin sensitivity of oral squamous carcinoma cells is regulated by $\mathrm{Na}^{+}, \mathrm{K}^{+}$-ATPase activity rather than copper-transporting P-type ATPases, ATP7A and ATP7B. Cancer Chemother Pharmacol 63: 643-650, 2009.

20. Hall MD, Okabe M, Shen DW, Liang XJ and Gottesman MM: The role of cellular accumulation in determining sensitivity to platinum-based chemotherapy. Annu Rev Pharmacol Toxicol 48: 495-535, 2008.

21. Hanahan D and Weinberg RA: The hallmarks of cancer. Cell 100: 57-70, 2000

22. Xu Y, Qu X, Zhang X, et al: Midkine positively regulates the proliferation of human gastric cancer cells. Cancer Lett 279: 137-144, 2009.

23. Hannun YA: Apoptosis and the dilemma of cancer chemotherapy. Blood 89: 1845-1853, 1997.

24. Shah MA and Schwartz GK: Cell cycle-mediated drug resistance: an emerging concept in cancer therapy. Clin Cancer Res 7: 2168-2181, 2001.

25. Stewart DJ: Mechanisms of resistance to cisplatin and carboplatin. Crit Rev Oncol Hematol 63: 12-31, 2007.

26. Qi M, Ikematsu S, Ichihara-Tanaka K, Sakuma S, Muramatsu T and Kadomatsu K: Midkine rescues Wilms' tumor cells from cisplatin-induced apoptosis: regulation of $\mathrm{Bcl}-2$ expression by Midkine. J Biochem 127: 269-277, 2000.

27. Mirkin BL, Clark S, Zheng X, et al: Identification of midkine as a mediator for intercellular transfer of drug resistance. Oncogene 24: 4965-4974, 2005. 